\title{
Laparoscopic pancreatic resections: review of feasibility, safety and outcome
}

\author{
K.B. Galketiya, V. Pinto, R. Perera, R. Rohankumar, N. Kumarasinghe, A. Shaminda \\ University of Peradeniya Teaching Hospital, Peradeniya, Sri Lanka
}

Key words: Laparoscopy; pancreatico-duodenectomy; distal pancreatectomy

\begin{abstract}
Pancreatico-duodenectomy and distal pancreatectomy are the curative resections for pancreatic malignancies. Minimal access resections will reduce the exposure incision whilst facilitating resection with a clear vision.

However surgeon faces a challenging learning curve which is less steep for distal resection compared to pancreaticoduodenectomy. In laparoscopic pancreatico-duodenectomy resection and anastomosis will be done by laparoscopy. In laparoscopic assisted pancreatico-duodenectomy some or all the anastomoses are performed by a mini-laparotomy.

In the case series presented three distal pancreatectomies were performed without conversion. Twenty three out of thirty two (74\%) pancreatico-duodenectomies were converted to open at various stages of resection. Five had complete mobilization, four had complete resection and minilaparotomy anastomosis.
\end{abstract}

One out of the four had the hepatico-jejunostomy performed laparoscopically. He had a pancreatico-gastrostomy and gastro-jejunostomy by a mini-laparotomy with an incision of about $5 \mathrm{~cm}$. Early feeding and mobilization was possible with analgesic requirement being minimal.

Two patients died with in one month in the pancreaticoduodenectomy group recording a mortality of $6 \%$. Except one all had clear resection margins on histo-pathology with lymph node clearance comparable to open surgery. In units performing open pancreatic surgery and conversant with advanced laparoscopy, going through the learning curve for laparoscopic pancreatic surgery is feasible and safe. To compare benefits over the open procedures warrant further recruitment of patients.

Correspondence: Galketiya KB

E-mail: kbgalketiya@yahoo.com.

Received: 06-01-2017 Accepted: 14-03-2017

(iD) http://orcid.org/0000-0002-7464-7371

DOI: http://doi.org/10.4038/sljs.v35i1.8351

(c) BY

\section{Introduction}

Surgical resection is the treatment for pancreatic malignancies for resectable tumours, Pancreaticoduodenectomy (PD) or distal pancreatectomy (DP). PD is associated with a significant morbidity and occasional mortality (1) which are comparatively less with DP.

Minimal access resection will minimize the incision and provide a better vision during surgery by magnification and zooming (8) with reduced blood loss $(2,3,4,5,9)$.

In PD anastomoses may be done laparoscopically or using a "mini" incision, as a laproscopic assisted procedure (LAPD) (4). The duration of surgery compared to open, is more in Laparoscopic pancreaticoduodenectomy(LPD) (2) whilst similar in distal resections (9). The learning curve is less steeper for distal resections (6).

The morbidity in laparoscopic resections are reported as similar to open $(2,9)$ Laparoscopic pancreatic surgery involves a challenging learning curve and literature indicate further studies to recommend it's routine use $(2,5,7,9)$. This case series provide a discussion on laparoscopic pancreatic resections, in a tertiary care center, in view of feasibility and outcome.

\section{Patients and method}

All patients undergoing laparoscopic pancreatic resections for a period of 3 years were included in this review.

Laparoscopic assisted pancreatico-duodenectomy(LAPD)

Patients were operated in supine position with $30^{\circ}$ head up and a tilt towards left. The legs were in abduction. Five ports were used. In the patients who underwent a complete resection anastomoses were performed by a mid line "mini”laparotomy.

\section{Laparoscopic distal pancreatectomy(LDP)}

The surgery was performed in right lateral position with a head up tilt. Five ports were used. In all spleen was removed en-bloc and the resected specimens were retrieved using a bag, fashioned with a "urinary catheter bag". 


\section{Results}

Details are discussed separately for both surgeries.

\section{Pancreatico-duodenectomy}

A total of thirty two patients underwent LAPD. In twenty three patients procedure was converted to open for completion of resection. Decision to open was made when the surgery is stagnant to the subjective feeling of the surgeon. In five patients the mobilization was completed laparoscopically but due to shortage of endostaplers laparotomy done for required division of organs.

In four patients who had resection laparoscopically anastomoses were performed by mid line laparotomy. In one of them hepatico-jejunostomy was performed laparoscopically requiring a mini-laprotomy of $5 \mathrm{~cm}$. In other three the incision was about $10 \mathrm{~cm}$

Stay in intensive care unit ranged from 48 to 96 hours. Two patients were readmitted to ICU with complications. On the first two post operative days pain was managed with epidural Bupivacain and subsequently with diclofenac suppositories and oral analgesics.

Two patients readmitted to ICU with sepsis needed ventilation and passed away making the mortality of the series $6 \%$. In thirty one patients the resection margins were clear and in one the margin was involved at the pancreatic resection margin. The lymph node removed ranged from 8-14.

\section{Distal pancreatectomy}

Three patients were operated, completed laparoscopically, without conversion. Non required ICU. Analgesic requirements were low, all being started on oral feeding and mobilized from next day. There were no complications and all discharged by six days. The resection margins were clear in all.

\section{Discussion}

Laparoscopic pancreatic resections pose a challenging learning curve $(2,5,6,8)$. Due to it's complexity LPD and LAPD are more challenging than LDP (8). This was evident in our series with all distal resections being completed laparosocpically whilst in LAPD 23 out of 32 had conversion prior to complete mobilization and or resection.

Regarding LAPD, the literature review by Gagner et al in 2009 of 146 surgeries, reports a conversion rate of $46 \%$.(3) In our series 23 out of $32(74 \%)$ were converted to open at various stages of resection. The experience our unit had in open pancreatic surgery, laparoscopy and observing videos on laparoscopic PD were useful to go through the learning curve. When the progress was slow a timely decision to open was made. At laparotomy, we identified the reasons for lack of progress. In the patients who had complete resection the incision size was smaller. Our incision size ranged from 6$10 \mathrm{~cm}$ compared to a mean size of $5.2 \mathrm{~cm}$ reported in a study. The patient who underwent laparoscopic resection and laparoscopic hepatico-jejunostomy had an incision of $5 \mathrm{~cm}$.

The efficacy of laparoscopy over open surgery to obtain clear resection margins and adequate lymph node harvest has different results in published series $(5,8)$. In our series results are similar in both techniques.

LDP-All three patients who underwent LDP were completed laparoscopically. Literature indicate less blood loss and short post operative stay in laparoscopic distal pancreatectomy whilst mean operative time and overall morbidity reported equal. These facts were evident in our patients.

\section{Conclusions}

Laparoscopic pancreatico-duodenectomy involves a steep and stretched out learning curve. Conversion to open surgery may be required until experience is gained. In units performing open procedure and conversant with advanced laparoscopy, going through this learning curve is feasible and safe. In contrast acquiring competency in distal pancreatectomy is less demanding. To compare benefits over the open procedures warrant further recruitment of patients.

All authors disclose no conflict of interest. The study was conducted in accordance with the ethical standards of the relevant institutional or national ethics committee and the Helsinki Declaration of 1975, as revised in 2000 .

\section{References}

1. Dirk J. Gouma, Rutger C. I. van Geenen,Thomas M. van Gulik, Rob J. de Haan, Laurens T. de Wit,Olivier R, C. Busch,Huug Obertop.Rates of Complications and Death After Pancreaticoduodenectomy: Risk Factors and the Impact of Hospital Volume. Ann Surg. Dec 2000; 232(6): 786-795. https://doi.org/10.1097/00000658-200012000-00007

2. Asbun HJ1, Stauffer JA.Laparoscopic vs open pancreaticoduodenectomy: overall outcomes and severity of complications using the Accordion Severity Grading System. J Am Coll Surg. 2012 Dec;215(6):810-9. doi: 10.1016/j.jamcollsurg.2012.08.006. Epub 2012 Sep 19. https://doi.org/10.1016/j.jamcollsurg.2012.08.006

3. Gagner M, Palermo M.Laparoscopic Whipple procedure: review of the literature J HepatobiliaryPancreat Surg. 2009;16(6):72630. doi: 10.1007/s00534-009-0142-2. Epub 2009 Jul 28. https://doi.org/10.1007/s00534-009-0142-2

4. Dulucq JL, Wintringer P, Stabilini C, Feryn T, Perissat J, Mahajna A. Are major laparoscopic pancreatic resections worthwhile? A prospective study of 32 patients in a single institution.SurgEndosc. 2005 Aug;19(8):1028-34. Epub 2005 May 26 https://doi.org/10.1007/s00464-004-2182-7 
5. Lei P, Wei B, Guo W, Wei H. Minimally Invasive Surgical Approach Compared With Open Pancreaticoduodenectomy: A Systematic Review and Meta-analysis on the Feasibility and Safety.Surg Laparosc Endosc Percutan Tech. 2014 Apr 16. [Epub ahead of print]

https://doi.org/10.1097/SLE.0000000000000054

6. Tan-Tam C, Chung SW.Minireview on laparoscopic hepatobiliary and pancreatic surgery. World J Gastrointest Endosc. 2014 Mar 16;6(3):60-67.

https://doi.org/10.4253/wjge.v6.i3.60

7. Bao PQ1, Mazirka PO, Watkins KT.Retrospective Comparison of Robot-Assisted Minimally Invasive Versus Open Pancreaticoduodenectomy for Periampullary Neoplasms. J Gastrointest Surg. 2013 Nov 15. [Epub ahead of print]
8. Zenoni SA1, Arnoletti JP2, de la Fuente SG2.Recent developments in surgery: minimally invasive approaches for patients requiring pancreaticoduodenectomy. JAMA Surg. 2013 Dec;148(12):1154-7. doi: 10.1001/jamasurg.2013.366.

https://doi.org/10.1001/jamasurg.2013.366

9. Zhang M, Fang R, Mou Y, Chen R, Xu X, Zhang R, Yan J, Jin W, Ajoodhea H. LDP vs ODP for pancreatic adenocarcinoma: a case matched study from a single-institution. BMC Gastroenterol. 2015 Dec 22;15(1):182. doi: 10.1186/s12876-015-0411-2. https://doi.org/10.1186/s12876-015-0411-2

10. KB Galketiya, MVG Pinto, Analysis of resection margins and lymph node dissestion in laparoscopic assisted pancreaticoduodenectomy. International Journal of Scientific and Research Publications February 2015;5(2) 